\title{
Social Interaction Effects on Fertility: Intentions and Behaviors
}

\author{
Les effets des interactions sociales sur la fécondité: \\ intentions et comportements
}

\author{
Clémentine Rossier • Laura Bernardi
}

Received: 11 February 2008/Accepted: 17 August 2009/Published online: 3 December 2009

(C) Springer Science+Business Media B.V. 2009

\begin{abstract}
The existing literature shows that the social interactions in personal networks affect individuals' reproductive attitudes and behavior through three mechanisms: social influence, social learning, and social support. In this article, we discuss the extent to which the socio-psychological model of the Theory of Planned Behavior (TPB) takes these social mechanisms into account when used in modeling fertility intentions and behavior. We argue that by integrating all three social network mechanisms, the ability of the TPB to explain reproductive events could be enhanced in two respects. First, social influence explains why some beliefs and practices are reproduced at the individual level even in the face of macro-level changes, and social learning mechanisms are crucial to distinguish who finally adopts new behavioral beliefs and practices in response to changes at the macro level. Second, social support relationships represent a capital of services to complement institutional provision (informal child care) as well as a capital of knowledge which helps individuals navigate in a complex institutional environment, providing a crucial element to explain heterogeneity in the successful realization of fertility intentions across individuals. The integration of the three social network mechanisms into the TPB helps to address the connection between changes in what the theory indicates as background factors and variation in individual intentions and behavior. We develop specific hypotheses concerning the effect of social interactions on fertility intentions and their realization and conclude with a critical review of the existing surveys that could serve to test these hypotheses and their limits.
\end{abstract}

C. Rossier $(\bowtie)$

Institut National d'Etudes Démographiques, 133 Boulevard Davout, 75980 Paris Cedex 20, France e-mail: clementine.rossier@ined.fr

L. Bernardi

Interdisciplinary Institute of Life Trajectories et Centre Pavie, Faculty of Social and Political Sciences, University of Lausanne, Bâtiment Vidy, 1005 Lausanne, Switzerland 
Keywords Social network - Social change - Fertility intentions · Fertility behavior · Low fertility

Résumé La littérature existante montre que les interactions sociales dans les réseaux interpersonnels influent sur les attitudes et comportements reproductifs des individus à travers trois mécanismes : par l'influence sociale, par l'apprentissage social et par le soutien social. Dans cet article, nous examinons dans quelle mesure le modèle psycho-social connu sous le nom de Theory of Planned Behavior (TPB) tient compte de ces trois mécanismes, en particulier lorsqu'il est utilisé pour modéliser les intentions et comportements féconds. Nous soutenons que la capacité de la TPB à expliquer les événements reproductifs pourrait être doublement accrue en intégrant l'ensemble des effets liés aux réseaux sociaux. Tout d'abord, si l'influence sociale explique pourquoi certaines croyances et pratiques sont reproduites au niveau individuel en dépit de changements intervenus au niveau macro, les mécanismes d'apprentissage social sont quant à eux cruciaux pour comprendre l'adoption de nouvelles croyances et pratiques en réponse à des changements macro. Deuxièmement, les réseaux de relations représentent un capital de services informels de garde d'enfant complémentaires aux services institutionnels, ainsi qu'un capital de connaissances qui aide les individus à naviguer un environnement institutionnel complexe, fournissant ainsi des éléments essentiels pour comprendre l'hétérogénéité dans la réalisation des intentions de fécondité constatée entre individus. L'intégration des trois effets liés aux réseaux sociaux dans la TPB aide à faire le lien entre des changements au niveau de ce que la théorie appelle des facteurs contextuels et des variations au niveau des intentions et comportements individuels. Nous développons des hypothèses spécifiques concernant l'effet des interactions sociales sur les intentions de fécondité et leur réalisation, et concluons avec une revue critique des données d'enquêtes qui pourraient servir à tester ces hypothèses et leurs limites.

Mots-clés Réseau social · Changement social · Intentions de fécondité · Comportement de fécondité · Basse fécondité

\section{Introduction}

The interplay between biological, psychological, relational, and social dimensions renders fertility decision-making and the realization of fertility intentions a rather complex process. Although fertility intentions have been shown to be good predictors of actual fertility (compared to socio-demographic characteristics), the match between intentions and realization is far from systematic. Actual fertility is generally below declared fertility intentions. For example, in France only $58.7 \%$ of the respondents who said that they wanted a child right away in 1998 had had one birth five years later (Toulemon and Testa 2006). This finding is not peculiar to France. In all low-fertility populations, the gap between fertility intentions and fertility behavior at the individual level is substantial (Bongaarts 2001). Why is that? 
Obviously, certain couples cannot implement their fertility plans for biological reasons (sub-fertility), but this group does not exceed the $4-5 \%$ of the population (Toulemon 1995). Other important factors are changes in the conjugal relation, a low quality partnership (Zabin et al. 2000), and changes in partner's fertility intentions (Williams 1992; Thomson 1997; Bankole 1995). Changes in the couple's economic status (Symeonidou 2000), and the cost of children linked to women's labor market participation and to child care arrangements have been found to be other factors explaining the discrepancy between fertility intentions and realization (Livi Bacci 2001). All these obstacles may lead to a delay in the transition to adulthood and a consequent postponement of fertility plans (Bongaarts 2001).

These studies move away from a purely individualistic approach to fertility behaviors, since they grasp fertility intentions and their realization as the product of couples' interactions, and mention the importance of factors such as institutions (labor market, child care arrangements) and values (importance of self-realization before forming a family) in shaping couples' wishes and actions. However, the different levels at which these factors affect the gap between fertility intentions and behaviors are not clearly articulated. Micro-level factors such as partnership history and partnership quality should be distinguished clearly from macro-level factors such as labor market conditions, availability of collective child care, and shared expectations toward the family. Further, if these studies do mention both micro and macro factors to explain the gap between fertility intentions and behaviors, they do not describe the mechanisms linking individual outcomes to macro conditions.

In this article, we propose to consider the gap between fertility intentions and realization by considering the role of individuals' interactions in social networks. Indeed, macro conditions shaping individual fertility such as family values, labor market conditions and the availability, and quality of collective child care, are learned and integrated by individuals during interactions with social network members. The experiences and evaluations of social network members, as well as the characteristics of the social interactions between them, are crucial to understand the way in which macro factors are filtered down and shape individual fertility (Kohler 2001). By focusing on social interaction effects, we can find out why some changes at the macro level are not immediately followed by a change at the micro level; and when change at the individual level does finally occur, we can understand where it starts and how fast it diffuses. Social interactions should also be considered as a resource which can be tapped by individuals to supplement institutional provision (as is the case of informal child care) or as a resource (a reservoir of knowledge) to better navigate complex institutional situations. Altogether, by studying social network effects on fertility intentions and behaviors, we will advance our understanding of how micro-macro factors interact to produce fertility outcomes that are below fertility desires in low-fertility populations.

Ajzen's "theory of planned behavior" (from now on TPB) (Ajzen 1988, 1991) gained credit among demographers as an economical means of framing the relationship between individual characteristics and beliefs, and the way the latter are linked to intentions and their realization. An extension of the theory of reasoned action (Fishbein 1967; Fishbein and Ajzen 1975), this is one of the family of sociopsychological models seeking to explain behavior through the mediation of 
behavioral intentions and addressing the open issue of the gap between intentions and realized behavior (see also Miller and Pasta 1995; Barber 2001). The theory has been used to study diverse demographic behaviors, such as contraceptive practice (see for example Sheeran and Taylor 1999; Van Landingham et al. 1995; Bennett and Bozionelos 2000) and young adults' departure from the parental home (Billari and Liefbroer 2007). When it comes to fertility, only one article can be cited (Liefbroer 2005). The data necessary to test the theory in the case of fertility were also collected in a Bulgarian survey (see Sect. 4.2 of this article), and first results have been presented (Billari et al. 2005). The theory is currently being tested for the first time on a large scale with data from the Generations and Gender Programme (GGP), the latest set of comparative European fertility surveys. Our purpose is not to criticize the model, but rather to understand to what extent it currently takes social network mechanisms into account, and to propose ways in which it could comprehensively do so. The aim is to argue for the added value of considering all three social network mechanisms in explanations of fertility intentions and behaviors in a TPB analytical framework.

According to the theory (Ajzen 1988, 1991), the occurrence of a specific behavior is predicted by two elements: individuals' intentions to behave in that way on the one hand (their "intention"), and their ability to do so on the other hand, given their skills and resources (their "actual behavioral control"). Individuals' intentions are shaped in turn by three factors: their perceived ability to perform the behavior ("perceived behavioral control") which depends heavily on their actual capacity to do it, their positive or negative evaluation of performing the behavior ("attitude toward the behavior"), and finally, their perception that significant others want them to behave that way ("subjective norm"). This last factor is what Ajzen calls the "social factor [of behaviors]; it refers to the perceived social pressure to perform or not to perform the behavior" (Ajzen 1991, p. 188). Through the concept of "subjective norm", the model takes social interaction effects partially into account.

In this article, we will first review the demographic literature on social network effects as applied to reproductive attitudes and behaviors (Sect. 2). We then propose a way to integrate social network mechanisms into the theory of planned behavior, and we develop a number of hypotheses about the possible role of social networks in widening or reducing the gap between (high) fertility intentions and (low) fertility outcomes (Sect. 3). Finally, we define what data would be necessary to test our hypotheses, and we review and critically evaluate existing survey modules devoted to social networks and fertility (Sect. 4).

\section{Literature Review: Social Network Effects on Demographic Behavior}

Individuals exchange information, services, and goods during social interactions. Social interactions can take place in lasting relationships with others, i.e., in social networks, or can be impersonal, for example when an individual learns something through the media or public observation. Montgomery and Casterline (1996) acknowledge the important impact of impersonal contacts in shaping reproductive ideals and practices. However, we will focus here only on the effect on fertility of 
interactions in social networks, i.e., on social network effects. Individuals' social networks are characterized by their size, the characteristics of their members (a network can be more or less varied, its members may have more or less experience of events related to reproductive processes), as well as by the intensity of each relationship, whether network members know each other (density of networks), what goods and services are exchanged by network members, the power structure between network members, etc.

The social psychological and the social network literature points to three main mechanisms by which social interactions between individuals and their network partners can have an impact on individual behaviors. In the demographic literature concerned with this topic, these three mechanisms have been coined "social learning", "social influence", and "social support". 1

Social learning processes have been extensively studied in the "diffusion of innovation" literature (see Kohler et al. 2007 for a recent review). This term refers to the acquisition of new information through informal interactions with others, whether through verbal exchange or observation. Social learning is typically at work when new techniques or new norms of behavior are introduced into a population, as for example when people started having children outside marriage in Japan (Rindfuss et al. 2004): these authors show that people observing an extra-marital birth in their social network are more likely to have one too. A repeated finding in the literature of social networks is that varied networks (i.e., networks whose members have different characteristics) favor social learning: for example, attitudes favorable toward AIDS prevention in Malawi are more frequent among individuals with a varied social network (Helleringer and Kohler 2005). Social learning can also matter in the absence of novelty. First, there is an age dimension to social learning: children and young people learn from networks what is already known by adults, as is the case, for example, for contraceptive use in the U.S (Montgomery and Casterline 1996). Also, in complex institutional situations, social learning allows individuals to reduce the uncertainty they face when taking decisions (Kohler 2001).

Social influence is a concept that covers several similar mechanisms. The first mechanism is the human tendency to conform to shared beliefs and practices in one's groups of affiliation, because of an innate need to reinforce one's own sense of identity by having it match the models conveyed by the groups to which one belongs. This mechanism can be called the "reference group effect" and has been shown to shape fertility intentions in a study conducted in Western Germany

\footnotetext{
1 Social capital, also sometimes used, is a generic term that includes individuals' social networks (their size and shape) as well as the diverse mechanisms which take place within them. It is interesting to note that social capital has a positive connotation, when defined as individuals' social networks and the resources these networks produce. For example, the literature of the influence of networks on individuals' health often emphasizes how belonging to tight social groups lowers individuals' stress levels, and how social support is crucial for the well-being of dependants. Morgan and Berkowitz King (2001) remind us, however, that social capital (defined more completely as individuals' social networks and the mechanisms which take place within them) can have negative outcomes as well, as, for example, when minority youth forfeit the chance of upward mobility because they wish to conform to and stay within their group of affiliation.
} 
(Keim et al. 2009; Bernardi et al. 2007): these authors found that being embedded in a network containing many persons who are pregnant or have a child fosters Ego's fertility intentions; also, if all close friends have children the respondents have a greater tendency to conform than if there is still one childless close friend left. Note that individuals tend to conform to their reference group while believing that they are taking purely personal decisions. The segment of the social network which matters here is relatively large: people with whom individuals are in frequent contact. A variation of the "reference group effect" is what Bernardi (2003) calls "contagion". A study in Italy showed that individuals' fertility decisions are often triggered by births in their social networks which foster an emotional reaction leading to conformity. A third mechanism, usually simply called "social influence" but actually referring to social pressure, occurs when an individual knowingly conforms to another person's wish or world vision because that person has a hierarchical advantage over him or her, or belongs to the group of emotionally significant others. For example, Helleringer and Kohler (2005) show that social pressure works against favorable attitudes toward AIDS prevention among women in Malawi, especially in the Northern patriarchal regions of the country where women live with their in-laws, and adopt their relatives' point of view that their husband is faithful, and hence, that AIDS prevention is unnecessary. These mechanisms-reference group effect, contagion, and social pressure-are somewhat difficult to disentangle and are close enough to be grasped with a unique concept, that of social influence. A repeated finding in the social networks literature is that dense networks favor social influence processes. Mechanisms of social influence explain why reproductive beliefs and practices do not change immediately in the face of macro-level changes. For example, a comparison between France and Germany showed that these two countries are characterized by widely different individual representations of formal child care and working mothers, each vision being strongly held by the majority within each country (in favor of formal child care in France and against it in Germany). These lasting dispositions can explain why fertility decisions are not sensitive to small variations in access to childcare in France (individuals adapt their lives to find child care where it is available, convinced of its benefits), and why it will take some time before new family policies and the development of formal child care structures have an impact on fertility in Germany, where most people think mothers should take full-time care of their children (Salles et al. 2008).

Finally, social support refers to the informal exchange of goods and services which can take place between network members. This dimension of social interactions has been extensively studied in the field of kin contributions to support of the elderly. A few authors have studied the impact of the informal exchange of childcare and other services and goods on individuals' motivation to have children and their ability to do so in Eastern European countries, where there is less formal (public or private) child care provision and income is lower than in Western European countries (Buehler and Philipov 2005; Buehler and Fratczak 2005; Philipov et al. 2006). In France, a country with an ample supply of formal child care, the availability of grandparents to look after small children does not seem to influence individuals' fertility intentions or realization (Salles et al. 2008). 


\section{Theoretical Framework and Hypotheses}

In light of this review of social network effects on reproductive behaviors, we propose four ways to link Ajzen's theory of planned behavior to social interaction mechanisms.

(1) In Ajzen's model, three factors influence an individual's intention to behave in a certain way: his positive or negative evaluation of the behavior ("attitudes toward the behavior"), whether significant others want him to adopt the behavior ("subjective norm"), and his belief that he has the capacity to implement the behavior ("perceived behavioral control"). We argue that Ajzen's definition of "subjective norm" broadly matches the concept of "social influence" as described in Sect. 2, except that to us, social influence can also occur through exchanges with and observations of weaker ties (through the reference group effect).$^{2}$

(2) Although it is possible to understand, through the concept of "social influence", why "attitudes" do not change from one generation to the next and tend to be similar across individuals belonging to the same social group, another concept is necessary to accommodate variations from the norm and new "attitudes". Departure from the norm does not occur systematically as a consequence of weakening social influence, and can, in fact, very well occur in contexts of strong social influence; here, change begins more slowly but accelerates over time, as was the case for the diffusion of positive attitudes toward AIDS prevention in patriarchal Northern Malawi compared to matriarchal Southern Malawi (Helleringer and Kohler 2005). As detailed in Sect. 2, a social network perspective suggests that social interactionobservations and discussions within the social network-is not only a source of social influence but also a source of social learning. Individuals use social learning in their larger networks (observation and conversations with significant others but also with people with whom they have weaker ties) to form their opinion about the advantages and disadvantages of new behaviors. The difference with respect to the "subjective norm" is thus the fact that departure from the norm rather than conformity is the point of interest: the fertility attitudes and practices of network members help to explain why some individuals adopt new attitudes, possibly in spite of attitudes and practices in their closer social network.

(3) Perceived behavioral control (PBC) refers to the perceived ability to perform a given behavior. It is determined by a set of "control beliefs" about the presence of factors that may facilitate or impede performance of the behavior. The strength of each control belief is weighted by the perceived power of the control factor and together they determine the prevailing perceived behavioral control. To the extent that perceived behavioral control is accurate, it can serve as a proxy of actual control and can be used to predict behavior. Actual

\footnotetext{
${ }^{2}$ Ajzen's recent work refers to how "observation" can be incorporated in measurement of "descriptive norms, i.e., whether important others themselves perform the behavior in question" (http://people. umass.edu/aizen/pdf/tpb.measurement.pdf, p. 6).
} 
behavioral control refers to the extent to which a person has the skills, resources, and other prerequisites needed to perform a given behavior. Successful performance of the behavior depends not only on a favorable intention but also on a sufficient level of behavioral control. The nearer PBC reflects actual control, the better intention is likely to be as a predictor of action. However, the socio-psychological literature abounds with examples in which perceived control is not accurate. The social network literature reviewed in Sect. 2 indicates that the extent to which individuals are able to reduce the uncertainty surrounding their reproductive decision (in TPB vocabulary: to match $\mathrm{PBC}$ to $\mathrm{ABC}$ ) depends, among other things, on social learning mechanisms. By taking into account the fertility attitudes and experiences of a large set of network members instead of only those of a small number of significant others, the impact of social learning on the gap between perceived and actual behavioral control can be measured.

(4) Also, depending on the institutional set-up (formal services and goods offered), and depending on their attitudes toward the behavior, close social network members may offer informal goods and services to help individuals implement the behavior. The "social support" offered by significant others will affect individuals' actual behavioral control as well as their perceived behavioral control. In others words, significant others matter in individuals' fertility intentions and their realization not only because of their attitudes toward fertility, but also because of the child care they may offer, and this mainly in settings with little formal child care provision.

Coming back to the gap between fertility intentions and outcomes, which interests us in particular, we can derive from what precedes the following hypotheses pertaining specifically to the discrepancy between fertility intentions and realization:

(1) When attitudes toward childbearing are particularly positive among individuals' significant others, their childbearing intentions will be strong because of social pressure, even when they do not have the actual means to have a child.

(2) The gap between fertility intentions and behaviors will be reduced when individuals have the opportunity to learn about new (lower) fertility ideals in their larger social networks, and reduce their fertility intentions.

(3) Social learning in their larger network helps individuals adjust their perceived behavioral control to their actual behavioral control, and thus reduces the gap between intentions and realization. Low levels of social learning (in networks composed of members with similar characteristics and little fertility experience) will go hand in hand with high levels of discrepancy between fertility intentions and outcomes.

(4) Social support by significant others (in the case of low fertility in Europe this dimension refers mainly to the availability of grandparents to supply informal child care) increases the resources that couples can mobilize to move from intentions to realization (actual behavioral control). A lack of social support will decrease couples' ability to realize their fertility intentions. 


\section{Review of Surveys Containing Information on Social Networks and Fertility}

Finding quantitative data to test these hypotheses has proven difficult, because this area of research is relatively new. The existing social network literature pertaining to reproduction allows us to draft a preliminary list of quantitative information needed to test social interaction effects on the gap between fertility intentions and behaviors (Sect. 4.1). We then review five (mostly) recent European surveys which included questions on both fertility (intentions and/or behaviors) and networks (Sect. 4.2). Although surveys containing both sets of questions are rare, we do not attempt here to make an exhaustive list of them: we picked a number of surveys presenting varied ways of asking fertility and social network questions. We describe the content of each questionnaire (fertility and social network sections), and then discuss to what extent these data could or could not be used to test (part of) our hypotheses.

\subsection{What Quantitative Dare Necessary to Test Social Interaction Effects on Fertility?}

Like in every empirical data collection enterprise, there will always be a trade-off between researchers' ambitions and resources. Hence, it is not realistic to think that a single large-scale representative survey could cover all influential and informative social relationships available to a single individual in different life domains such as family, job, and leisure activities, to quote just a few. Based on empirical case studies, we can make grounded hypotheses about which information is likely to be more relevant and which we can set aside in the interest of efficient use of our scarce resources (Keim et al. 2009). Emotionally close ties, such as partners, parents, close friends, siblings, and cousins, influence Ego's intentions and behavior by providing support, exerting pressure and serving as points of reference and role models; they are also most effective for emotional contagion. Weak ties, such as other friends, colleagues, neighbors and acquaintances, influence Ego's intentions and behavior mainly by providing grounds for social learning and by serving as reference groups for comparing Ego's life arrangements with that of others. The fertility experiences of network partners matter, as well as their attitudes toward fertility, and their availability to offer informal childcare, on top of their socio-demographic characteristics and the density of relations between network members.

On this basis, we can suggest a minimal set of information necessary to appropriately estimate social network effects on fertility intentions, their determinants and their realization. Ideally, the survey should be designed as a panel of at least two waves (and ideally three) to disentangle causality in network structure and dynamics, and fertility intentions and realization. Data collected at each wave should cover different sets of information about the network partners of egocentered networks.

First, the name generators should be chosen to make sure that information about emotionally close individuals (or significant others) is collected, since they are crucial for appreciating social pressure. As this set of relationships varies relatively 
little through time, a time reference is not always necessary here. Reference group effects should be captured by including information on individuals with whom ego is frequently in contact (colleagues and people with whom individuals are engaged in social activities in a given time frame). Occasional conversational partners with whom ego discusses themes like parenthood and children should be recorded for social learning effects. Conversational network partners or frequent contacts can fluctuate a great deal, depending on the places frequented by the respondent at a given moment in time (neighborhood, job, and school, etc.,) and on changes in the respondent's centers of interest; conversational partners and frequent contacts should thus be captured in reference to a precise period of time (in the year preceding the survey for example). In short, we suggest collecting a list of significant others, a list of frequent social contacts, and a list of conversational partners. An indication of the nature of the relationship (relative, close friend, other friends, and colleagues) and of its duration helps classify network members according to the strength of ties (closer or weaker).

Second, for each network member, a certain number of characteristics should be recorded. Given that this is usually a time-consuming part of the questionnaire, a limit should be set on the number of alters about whom we record these details. Alters' fertility ideals, their number of children and the age of these children are necessary to study social influence (conformity to prevailing norms and practices) as well as social learning effects (adoption of new attitudes and behaviors). Alters' ability to provide informal childcare should also be recorded to test for social support effects. The socio-demographic characteristics of network members and the density of the relationships between network members can help in identifying social influence and social learning effects, since varied networks are usually associated with greater social learning and dense networks are usually associated with greater social influence.

By contrast, in a TPB approach, only a list of significant others would be generated, and they would be asked whether they wish Ego to have a(nother) child soon.

\subsection{Review of Recent European Surveys with Data on Fertility and Social Networks}

To what extent do current surveys containing data on fertility and social networks conform to this ideal list? Let us examine in detail the content of five surveys conducted in recent years in different European countries.

\subsection{1 “The Young People: Partnership, Marriage, Children”, 2002, Bulgarian Academy of Sciences.}

This cross-sectional survey collected data on respondents' past reproductive history, and on their current fertility intentions. It was designed, among other things, to capture the effect of the "subjective norm" (based on Ajzen's model) on fertility intentions, and is thus of special interest to us. 
The list of network members is constructed in a sophisticated manner. The respondent is asked a series of network generating questions: from whom he received or to whom he gave help (a lot or a little) during the last 2 years, who borrowed money from him, and from whom he borrowed money during the same period, with whom he talked about worries, about marriage, about children, and about contraception during the last 2 years, and whether he knows people who are well-informed. As an answer to each of these questions, the respondent writes down a list of a maximum of five persons on a piece of paper, numbering each of these names. If the name of a person has already been mentioned in a response to a previous question, the respondent does not write it down again; if the name has not been mentioned yet, the respondent adds it to the list. For each question, the respondent only gives the interviewer a series of numbers, taken from the list of names which lengthens as the questions unfold. Finally, the respondent is asked to add to his list the names of all the persons who are important to him, if they do not appear already on the list; there is no number limit here. In a second step, the respondent is asked to select from his list the five persons who are most important to him. For each of them, the interviewer asks how many children these persons have, and whether they would approve if the respondent had a child in the next 2 years. The respondent is finally asked whether these five people know each other, and for each of them: his or her relationship with the respondent, his or her sex, and how close they are geographically and emotionally.

We should first note, and in line with our own pre-occupations, that although this survey is well suited to study the formation of fertility intentions, it is obviously ill designed to study the gap between fertility intentions and behaviors (no follow-up survey). Second, the network generator questions are designed to select the most important network members: such a list is suited to the study of social influence and social support effects. What about the network members' recorded characteristics? The questions on network density, on emotional proximity, on the number of children and on the response of the five most important network members to the respondent having a(nother) child soon are all well suited to studying social influence effects on fertility intentions. The data can also be used to study the effect of social support on fertility intentions, by studying whether the respondent's parents and parents-in-law (when on the short list of "important people") live nearby, are emotionally close, and exchange help with the respondent; a direct question on the possibility of getting child care from these close network members would have been even better. Altogether, although the data are well suited to study social influence effects on the formation of intentions, and can be used to study social support effects, information is missing to study social learning. However, some of the network generator questions ask about people with whom the respondent discussed family matters: a list of these people could be used to study social learning effects. It should be complemented by a list of persons with whom the respondent interacts frequently. We would also need to know the characteristics of these informational/reference persons: at the very least their age, number of children, their desired family size, their educational background, their relationship with the respondent, and their place of residence. 


\subsection{2 “Proches et Parents", 1990, Institut National d'Etudes Démographiques.}

This cross-sectional survey collected data on respondents' past reproductive history. It was designed to identify individuals' close social network and its impact on individual life histories (Bonvalet et al. 1993, 2007; Bonvalet 2003). Although it is not as recent as the other surveys, we included it in our analysis for its in-depth approach to individuals' significant others.

The network generator question is preceded by a large number of questions pertaining to the influence of significant others on the respondent's life and to the exchange of help and services with kin and other close network members: from the start, the focus is on the persons who mattered most to the respondent during his or her entire life. Respondents were asked the following questions:

- who lives with you (maximum 12 names can be given),

- do you share the same occupation as a close network member (max three names),

- did you ever work in the same business as a close network member (max two names),

- did you ever work in a business owned by a close network member (and vice versa) (max two names),

- did you ever have other professional relations with a close network member (max 2 names),

- did you take over as the head of a business after a close network member (max one name),

- did you inherit a business from a close network member (max one name),

- did a close network member put you in contact with an employer (and vice versa) (max two names),

- has a close network member otherwise played an important role in your working life (and vice versa) (max two names for the first question max three names for the second question),

- have you lived in the place owned by a close network member,

- have you gotten help from a close network member to find housing (and vice versa),

- to pay the deposit to rent a dwelling (and vice versa),

- to pay the rent (and vice versa),

- to pay the down payment to buy a house (and vice versa),

- to build your house (and vice versa),

- has a close network member given you other help concerning housing (and vice versa) (all the questions on housing have a maximum of two names),

- were some close network members a model to you when growing up (max two names),

- do family gatherings occur at the place of some specific close network members (max two names),

- do you prefer to avoid some network members (max four names),

- do you regularly help close network members with: childcare (and vice versa) (no limit on number of names), 
- elderly care (and vice versa) (no limit on number of names),

- lend your house for vacation (and vice versa) (no limit),

- other forms of help (and vice versa) (no limit),

- have you supported a close network member during difficult times (and vice versa) (max four names for the first question, nine names for the second).

After these questions, the respondent is asked to list all his close network members, family, and friends (up to 20 names), without referring to the previous questions (the names listed may have been mentioned already or may not, and some people mentioned earlier may not be on the final list). Respondents are then asked to give a number of characteristics for each person on the final list. The characteristics recorded depend on whether the person is a direct relative of the respondent or not (direct relatives are spouses, parents, grand parents, children, brothers and sisters, and uncles and aunts); direct relatives are investigated whether they are considered as a "close network member" or not. For these people, we know the frequency of contacts and geographical proximity, their sex, age, place of residence, marital status, number of children, occupation, whether they own their dwelling, and their spouse's occupation. For other close network members, the same information is collected (except for the frequency of contacts), with additional questions on how they met and the length of the relationship.

We should note first that these data allow us to study social interaction effects on past fertility behaviors, but not on fertility intentions or on the realization of fertility intentions, which seriously limits the usefulness of these data for our purpose. What is remarkable in this data collection effort, however, is the great attention paid to the varied aspects of "closeness", as well as the size of the network on which information is collected (up to 20 close network members and all next of kin). Since the network generator question is targeted on "close network members" and next of kin, the listed network members are more likely to be involved in social influence or social support processes than in social learning. In order to study social learning effects, a list of network members with whom the respondents discusses family matters may be more pertinent. Another interesting aspect of this survey is the time frame used to collect the list of network members. Although the network generator question pertains to close network members at the time of the interview, the large set of questions just preceding it focuses on people with whom the respondents have maintained relations since childhood or early adulthood, which is fine when studying social influence or support effects. Finally, focusing on the characteristics of recorded network members, we note the absence of questions on whether the network members know each other (an important dimension when studying social influence effects); moreover, the lack of data on network members' desired number of children make it difficult to study social influence effect on those network members who have not yet finished their family formation. The question on child care received in the past is pertinent for studying the impact of social support on past fertility behavior, but a question on the likelihood that a close network member will offer child care in the future would be more appropriate if the focus was on future fertility intentions. 


\subsection{3 "Intentions de Fécondité », 1998-2003, Institut National d'Etudes Démographiques.}

This survey, conducted in 1998, asked respondents about their fertility intentions for the next 2 and 5 years in great detail, introducing varied time frames and degrees of certainty for the intentions expressed, and asking about the intentions of both partners. Fertility intentions and realization were captured again for the same individuals in two short postal follow-up surveys in 2000 and 2003. The 1998 survey was a households' living conditions study to which a module on fertility intentions was added; the same survey contained another module (designed to study old age support) on the respondents' social contacts. As a prospective study of fertility intentions and their realization is ideal for studying the formation of fertility intentions and the gap between fertility intentions and behaviors, we wondered whether the social contacts variables collected could be used to study social interaction effects on fertility.

This survey does not contain a network generator question, unlike all the other surveys analyzed so far: it, therefore, has no list of close network members or of conversational partners or frequent contacts. What it does contain is the number of annual visits to the mother and the father (if not living with the respondent and alive), the number of annual visits with other non-cohabiting members of the family of origin, the number of annual visits to friends and to neighbors. There are also a number of questions on the amount of contacts with colleagues (for respondents who work outside of their homes): whether they lunch with their colleagues most of the time, whether they see their colleagues outside of work, the frequency of visits to colleagues' homes and visits from colleagues to the respondent's home. Finally, we know how many associations the respondents belongs to (out of for 14 types of associations: political, musical, sports, and parents' association, etc.,), and for each of them, whether the respondent assumes a leadership role, and how often he or she participates in the association's activities.

In contrast to the two questionnaires already reviewed, the focus here is not only on "close network members", but also on colleagues, on neighbors and on shared leisure activities, which makes this survey potentially useful for studying social learning effects. However, because we do not have a list of the network members encountered by respondents at work, in their neighborhood and in associations (we just know how often the respondents have face-to-face social interaction with colleagues, neighbors and in associations), we also do not know the characteristics of the respondents' weaker ties. We also have almost no information on the respondents' close network members: we do not know anything about these network members' family formation behaviors and attitudes, or whether the respondent's network is dense or varied. Obviously, although the frequency and the source of social interactions are important to understand some aspects of the well-being of the elderly, these dimensions are of no help when trying to study the impact of social interactions on fertility intentions and behaviors. Rather than the size and source of social interactions, what matters to us is what close network members think about family formation, how they act, and how influential their position may be, whether 
they can help with child care, and how exposed individuals are to varied information concerning family formation.

\subsection{4 « Devenir Parents», 2006-2008 PAVIE- Center (Université de Lausanne).}

The first wave of this longitudinal survey targeted couples who were expecting their first child. The survey is designed to understand the impact of the arrival of a first child on their life-course trajectory and their social networks. We should underline that the survey was not designed to study the determinants of fertility intentions and behaviors; the specific nature of the sample, if well suited to the study the consequences of childbearing, is understandably less appropriate for studying the formation of fertility intentions and their realization. The first and the third waves contain respondents' fertility intentions (whether they want more children in the future and if yes, how many) as well as some data on the respondents' social networks.

The network generator question is phrased as follows: can you list all the persons who were important to you (in a positive or negative way) during the last 12 months? A maximum of 16 names can be mentioned. For each of these persons, a number of characteristics are recorded: type and length of relationship, sex, age, place of residence, profession, and age of the smallest child; we also know whether the person has been cited for having played a negative role in the respondent's life. For each of the first five persons cited, additional information is collected: we know the respondent's frequency of contact with that person, whether they would give the respondent emotional support in case of a small problem, and would give sizeable domestic support in case of a larger problem. The same information about contact and support is collected for all the members on the short list.

First, we should underline that, unlike the preceding survey, data on fertility intentions are rather minimal here (no time frame, for example), making it difficult to match these intentions with future births captured in later waves of the survey. Also, since the focus is on couples expecting their first child, the variation in fertility intentions is smaller here than in the general population: we do not have people who postpone family formation to a later date or who do not want children at all. Finally, the first pregnancy may not be the best time to ask about future fertility intentions, since there is usually a lot of uncertainty about the healthy outcome of the pregnancy at that stage: many respondents may answer that they do not know what their future fertility intentions are.

The network generator question adopts the "close network members" approach: respondents are asked to list the people who are important to them, making these data suited to studying social influence and social support effects (and less suited to studying social learning effects). We know whether these important network members (five of them) know and support each other, and this detailed information on density is also pertinent to study social influence effects. However, the survey lacks information on these network members' attitudes and behaviors concerning family formation (number of children, desired number of children, and whether they approve of the respondent having children), thereby making social influence in the 
specific area of family formation difficult to investigate. The survey also contains information on the support offered by the short list of important network members (distinguishing emotional and practical domestic support in case of problems): these data could be used to test the effect of social support on fertility intentions and realization, although the support offered in the case of problems may be a weak indicator of future and lasting child care. Finally, the survey contains an interesting question on the age of the last child, which could be a good indicator of the respondent's exposure to information about family formation, interesting to study social learning effects. Unfortunately, we do not have the list of persons with whom the respondent exchanges information about family formation: it is therefore difficult to test whether varied and numerous sources of information on family formation lead to more innovative fertility intentions and, using data on fertility realization between the two waves, to more realistic fertility intentions.

\subsection{5 “Etude des Relations Familiales et Intergénérationnelles » (ERFI), 2005, INSEE and INED.}

This survey is the first wave of the French contribution to the GGP. Countries which have chosen to undertake the survey are currently at different stages of realization, and have some latitude to modify the standard questionnaire. Fertility intentions variables are captured in detail in this questionnaire whose main purpose is to study fertility decisions: these data will allow researchers to compare the births reported in waves 2 and 3 to intentions reported in earlier waves.

However, data on social interactions are meager in the GGP questionnaires, and ERFI is no exception. We know whether respondents get help from network members for the care of their current children: however, when studying the impact of social support on fertility intentions and future realization, we need to have data on the possibility of getting child care in the future. The questionnaire contains data on the frequency of visits, geographical proximity, and quality of the relationship with children who have left the respondent's home and with the respondent's biological parents. These data are valuable to study intergenerational relationships and support (one of the themes of the survey), but cannot be used to study social influence on fertility. Indeed, to study social influence, we need to look at a set of network members who are important to respondents of childbearing age (parents are not the only eligible members in this list), and we need to know these peoples' attitudes toward the respondent's childbearing decisions and their own fertility intentions and behaviors. Finally, there are no data in this survey which could allow us to study social learning effects.

\section{Conclusion}

This article is an effort to bring social interaction (or social network) effects into the focus of demographers currently thinking about the determinants of low fertility in Europe. Its aim is to offer a theoretical and operational toolbox to researchers interested in studying social interaction effects on fertility, and to help in convincing 
others of the importance of taking these mechanisms into account when studying fertility or any other demographic behavior.

In order to achieve our theoretical objective, we extended the Theory of Planned Behavior, a socio-psychological value expectancy model currently popular among demographers studying fertility, and which integrates fertility intentions as an important determinant of fertility behaviors. We explain how all three social network mechanisms identified in the literature can be integrated into the model: social influence, social learning, and social support. Social influence helps explain why individuals share their significant others' and larger social group's positive attitudes toward family formation, even in contexts where macro-social change has rendered having children more difficult. However, the diffusion of new or previously deviant beliefs (such as choosing not to have children), and ultimately enduring social change, cannot be explained without the intervention of "social learning" mechanisms: indeed the adoption of new ideas cannot be related simply to low levels of social influence, since it depends rather upon the existence, within a larger circle of relations, of new models of behavior. Also, "social learning" is one mechanism through which individuals form realistic fertility intentions (have a "perceived behavioral control" close to "actual behavioral control" in TPB terms): we argue that interactions in social networks constitute an important resource enabling individuals to form realizable intentions. Finally, we propose to add informal child care as one element of the resources ("actual behavioral control" in TPB vocabulary) available to individuals to realize their fertility intentions: this factor may be important to understand fertility decisions and behaviors, especially in contexts lacking formal child care.

Why should we add social network theory to the TPB model, which has otherwise proven useful? We argued in this article that it is crucial in two respects to integrate all social network mechanisms in models such as the TPB when studying fertility. First, the model can explain, through mechanisms of social influence why changes in representations of parenthood and ideal family size can be slower than changes in socio-economic conditions and institutions. Social learning mechanisms, on the other hand, are crucial to distinguish who adopts new behavioral beliefs and practices, when change at the macro level finally sinks in. With the inclusion of both social influence and social learning mechanisms, the theory can map the link between macro-level changes and micro-level changes in behavioral intentions. Second, social interaction is important to fertility because relationships are a capital that can complement institutional provision (social support in the form of informal child care) as well as a capital of knowledge which helps (through social learning) individuals navigate in a complex institutional environment, providing a crucial element to explain heterogeneity in the successful realization of fertility intentions across individuals.

After elaborating four testable hypotheses about the role of social network effects on the gap between fertility intentions and realization, we outlined the quantitative survey information which would be necessary to test them. We examined five (mostly) recent surveys including questions both on fertility and on social networks, and we concluded that none could be used to test all our hypotheses. This analysis illustrates, however, some important operational aspects to be taken into 
consideration for future quantitative studies of social interaction effects on fertility. It appeared essential to collect lists of network members, since what matters most in this area of study are the characteristics of different types of network members: both French surveys "Intentions de Fécondité" and "ERFI" are of little use because they lack such lists. Our analysis also showed how to generate lists of varied network members: the Bulgarian "Young People" survey, the Swiss "Devenir Parents", and the French "Proche and Parents" focus on significant others which are necessary to study social influence and social support effects, but all five surveys provide interesting questions which could be used to generate lists of weaker ties, needed to study social learning effects. The French survey "Proches and Parents" and the Bulgarian survey "Young People" are relatively complete regarding the list of characteristics to be collected for each network member, although we suggest some additions. Finally, the "Proches and Parents" survey, which adopted a life-course approach, helped us think about the appropriate timeframe to capture network members (it has to be short for weaker ties, but can be longer for strong ties).

Acknowledgments This research was carried out as part of the project "Fertility intentions and outcomes: The role of policies to close the gap" supported by the European Commission, DG "Employment, Social Affairs and Equal Opportunities" (Contract Number: VS/2006/0685).

\section{References}

Ajzen, I. (1988). Attitudes, personality, and behavior. Chicago: Dorsey Press.

Ajzen, I. (1991). The theory of planned behavior. Organizational Behavior and Human Decision Processes, 50, 179-211.

Bankole, A. (1995). Desired fertility and fertility behavior among the Yoruba of Nigeria: A study of couple preferences and subsequent fertility. Population Studies, 49(2), 317-328.

Barber, J. S. (2001). Ideational influences on the transition to parenthood: attitudes toward childbearing and computing alternatives. Social Psychological Quarterly, 64(2), 101-127.

Bennett, P., \& Bozionelos, G. (2000). The theory of planned behaviour as predictor of condom use a narrative review. Psychology Health \& Medicine, 5(3), 307-326.

Bernardi, L. (2003). Channels of social influence on reproduction. Population Research and Policy Review, 22(5-6), 527-555.

Bernardi, L., Keim, S., \& von der Lippe, H. (2007). Social influences on fertility: A comparative mixed methods study in eastern and western Germany. Journal of Mixed Methods Research, 1(1), 23-47.

Billari, F. C., \& Liefbroer, A. C. (2007). Should I stay or should I go? The impact of age norms on leaving home. Demography, 44, 181-198.

Billari, F., Philipov, D., \& Testa, M.-R. (2005). Attitudes, subjective norms and perceived behavioral control as predictors of union formation intentions. In IUSSP conference, Tours, France.

Bongaarts, J. (2001). Fertility and reproductive preferences in post-transitional societies. Global fertility transition. Population and Development Review, 27(Suppl), 260-281.

Bonvalet, C. (2003). The local family circle. Population, 58(1), 9-42.

Bonvalet, C., Gotman, A., \& Grafmeyer, Y. (2007). Family kinship and place in France. London: Southern Universities Press.

Bonvalet, C., Maison, D., Le Bras, H., \& Charles, L. (1993). Proches et parents. Population, 48(1), 83-110.

Bühler, C., \& Fratczak, E. (2005). Learning from others and receiving support: The impact of personal networks on fertility intentions in Poland. MPIDR working paper, 2005-2017.

Bühler, C., \& Philipov, D. (2005). Social capital related to fertility: Theoretical foundations and empirical evidence from Bulgaria (pp. 53-81). Vienna: Vienna yearbook of population research 2005.

Fishbein, M. (1967). Attitude and the prediction of behaviour. In M. Fishbein (Ed.), Readings in attitude theory and measurement. New York: Wiley. 
Fishbein, M., \& Ajzen, I. (1975). Belief, attitude, intention, and behavior: An introduction to theory and research. Reading, MA: Addison-Wesley.

Helleringer, S., \& Kohler, H.-P. (2005). Social networks, perceptions of risk, and changing attitudes towards HIV/AIDS : New evidence from a longitudinal study using fixed-effects analysis. Population Studies, 59(3), 228-265.

Keim, S., Klärner, A., \& Bernardi, L. (2009). Fertility-relevant social networks: composition, structure, and meaning of personal relationships for fertility intentions. MPIDR Working Paper, 2009-2028.

Kohler, H.-P. (2001). Fertility and social interaction: An economic perspective. New York: Oxford University Press.

Kohler, H.-P., Behrman, J. R., \& Watkins, S. C. (2007). Social networks and HIV/AIDS risk perceptions. Demography, 44(1), 1-33.

Liefbroer, A. C. (2005). The impact of perceived costs and rewards of childbearing on entry into parenthood: Evidence from a panel study. European Journal of Population, 21(4), 367-391.

Livi Bacci, M. (2001). Comment: Desired family size and the future course of fertility. Global fertility transition. Population and Development Review, 27(Suppl), 282-289.

Miller, W. B., \& Pasta, D. J. (1995). Behavioral intentions: Which ones predict fertility behavior in married couples? Journal of Applied Social Psychology, 25(6), 530-555.

Montgomery, M. A., \& Casterline, J. B. (1996). Social learning, social influence and new models of fertility. In J. B. Casterline, R. D. Lee, K. A. Foote (Eds.), Fertility in the United States: New patterns, New theories. Supplement to Population and development Review, 22, 151-175.

Morgan, P. S., \& Berkowitz King, R. (2001). Why have children in the 21st century? Biological predisposition, social coercion, rational choice. European Journal of Population, 17(1), 3-35.

Philipov, D., Spéder, Z., \& Billari, F. (2006). Soon, later, or ever: the impact of anomie and social capital on fertility intentions in Bulgaria (2002) and Hungary (2001). Population Studies, 60(3), 271-288.

Rindfuss, R. R., Bumpass, L. L., Choe, M. K., \& Tsuya, N. O. (2004). Social networks and family change in Japan. American Sociological Review, 69(6), 838-861.

Salles, A., Rossier C., \& Brachet S. (2008). Understanding the long term effects of family policies on fertility: the diffusion of different family models in France and Germany. In EAPS Conference, Barcelona. 10-12 July 2008.

Sheeran, P., \& Taylor, S. (1999). Predicting intentions to use condoms: A meta-analysis and comparison of the theories of reasoned action and planned behavior. Journal of Applied Social Psychology, 29(8), 1624-1675.

Symeonidou, H. (2000). Expected and actual family size in Greece: 1983-1987. European Journal of Population, 16(4), 335-352.

Thomson, E. (1997). Couple childbearing desires, intentions and births. Demography, 34(3), 343-354.

Toulemon, L. (1995). Très Peu De Couples Restent Volontairement Sans Enfant. Population (French Edition), 50(4/5), 1079-1109.

Toulemon, L., \& Testa, M.-R. (2006). Fertility intentions and actual fertility: A complex relationship. Population and Societies, (415), 4.

Van Landingham, M., et al. (1995). Two views of risky sexual practices among northern Thai males: The health belief model and the theory of reasoned action. Journal of Health and Social Behavior, 36, 195-212.

Williams, L. B. (1992). Who decides? Determinants of couple cooperation and agreement in U.S. fertility decision. Populations Studies Center, University of Michigan Research Reports, No. 92-238.

Zabin, L. S., et al. (2000). Partner effects on a woman's intention to conceive: Not with this partner. Family Planning Perspectives, 32(1), 39-45. 